\title{
A stereological and ultrastructural approach to fetal and newborn rat pancreas
}

\author{
M. Eyüp Altunkaynakª, B. Zuhal Altunkaynak ${ }^{a *}$, Deniz Ünal ${ }^{b}$ Ömür Deniz ${ }^{a}$ Özgen Vuraler ${ }^{\mathrm{b}}$, Bünyami Ünal \\ ${ }^{a}$ Department of Histology and Embryology, Faculty of Medicine, Ondokuz Mayls University, Samsun, Turkey \\ ${ }^{b}$ Department of Histology and Embryology, Faculty of Medicine, Atatürk University, Erzurum, Turkey
}

\section{ARTICLE INFO}

ABSTRACT

\section{Article History \\ Received 25/12/2012 \\ Accepted 28/06/2013}

\section{* Correspondence to:}

Berrin Zuhal Altunkaynak

Department of Histology and Embryology,

Faculty of Medicine,

Ondokuz Mayıs University, Samsun, Turkey

e-mail: berrinzuhal@gmail.com
The pancreas is an important organ, which contains two distinct populations of cells, the exocrine cells that secrete enzymes into the digestive tract, and the endocrine cells that secrete hormones into the bloodstream. We studied the pancreas of rats which divided into two groups referred to 20-days-old rat fetuses and three-days-old newborns via both with quantitative and microscopical methods. At the end of the study; pancreas samples were obtained from all animals. Stereological estimations were performed on total pancreas volume, Langerhans islet's volume and islet cell number. The histological structure of pancreases of these two groups was also evaluated at light and electron microscopical levels. According to our results; morphological differences between fetuses and newborns, were statistically significant. These results indicate that rat's pancreas development continues after the birth. Further studies needed to determine of that question which period of life pancreas development is complete.

J. Exp. Clin. Med., 2013; 30:147-151
Keywords:

Electron Microscopy

Embryology

Pancreas

Rat

Stereology

\section{Introduction}

Pancreas is an important organ which produces a lot of digestive enzyme and some major endocrine hormones. Over the last decades, development of pancreas has been widely investigated. This process may be summarized as following at the foregut/midgut junction the septum transversum generates two pancreatic buds (dorsal and ventral endoderm) which will fuse to form the pancreas. The dorsal bud arises first and generates most of the pancreas. The ventral bud arises beside the bile duct and forms (Michaela Dixon et al., 2009) only part of the head and uncinate process of the pancreas. The mature pancreas has both exocrine and endocrine functions. In the fetal period cell clusters differentiate from pancreatic bud endoderm. These cell clusters form acini and ducts (exocrine). On the edge of these cell clusters pancreatic islets (endocrine) also form (Hill, 2007). Stereology provides reliable and quantitative results to us so as to do estimations which cannot be calculated by any mathematical and traditional methods.
If you have two dimensional objects obtained from real three dimensional samples such as metallurgical objects, magnetic resonance (MR), tomography or histological images, thus, stereology can be performed on these images. There are many studies on pancreas; some of these are clinical, anatomical and embryological (Chung et al., 2007; Marchetti et al., 2007). But neither these studies give any quantitative results nor there are stereological features about pancreas in literature. We prefer Sparague dawley rats because their gestation period is shorter than other mammalian and also rat model is appropriate for prediction of physiological, pathological histological or embryological mechanisms in human.

In this study, we histologically and stereologically evaluated pancreases of 20 days old fetuses and newborn rats. For this aim we estimated volume of total pancreas and pancreatic islets and number of islet cells. Also we investigated histological structure of developing pancreas at both light and electron microscopical levels. 


\section{Materials and methods}

\section{Experimental procedure and animals}

In this study, 20-days-old rat fetuses and newborn pups were used. For this purpose female and male Sprague dawley rats, weighing approximately 250-300 gr were mated in the laboratory of The Experimental Research and Application Center (Atatürk University, Erzurum, Turkey) during the night.

The morning on which sperm positive smears were obtained was declared gestation day 0 . Pregnant females $(n=6)$ were housed individually under standard conditions $(12: 12 \mathrm{~h}$ light-dark cycle at $22 \pm 2{ }^{\circ} \mathrm{C}$ ) and offered food and water ad libitum. Fetuses and newborn pups (in post natal third day; $\mathrm{n}=10$ ) were obtained at the 20th day and end of the gestation period, respectively. Pancreas samples prepared for histological and morphometrical measurements. Gender was not considered among the fetuses and newborns.

All surgical procedures proceed according to local ethic committe rules (29.06.2005:5/1)

\section{Tissue processing for stereological and light microscopic analyses}

The pancreas samples were removed from all animals and these tissues were fixed in 3\% glutaraldehyde in $0.1 \mathrm{M}$ phosphate buffer, post-fixed in 1\% phosphate-buffered osmium tetroxide, dehydrated in a graded acetone series, and washed in propylene oxide for electron microscopic examination. After dehydration, specimens were embedded in fresh Araldite CY 212 (Agar, Cambridge, UK). Sections were cut using an ultramicrotome (Nova LKB Bromma, Sweden). Firstly, each araldite-embedded tissue block was serially cut into $1-\mu \mathrm{m}$ thickness. These semi-thin sections were stained with toluidine blue for light microscopical examination and stereological analyses. Secondly, tissue samples were cut into 70-80 nm section-thicknesses for histological evaluation at the ultrastructural level. These thin sections were stained in $2 \%$ uranyl acetate and $0.4 \%$ lead citrate, and examined using Jeol 100 SX transmission electron microscope (Jeol, Tokyo, Japan).

\section{Stereological analyses \\ Pancreas volume}

For volumetric estimation procedure, every fifth section was selected through a set of consecutive sections from each pancreas samples. Choosing the first section was done randomly. Fifteen to twenty sections were sampled from each rat pancreas in a systematic random manner (Gundersen et al., 1999). Selected sections were photographed on the personal computer (PC) screen using a light microscope (Olympus BH-2, Japan) with a digital color camera attachment (Sanyo VVC-6975P, Japan) and dial indicator. Unbiased Cavalieri method was applied to the light microscopic images for the stereological estimation of volume of pancreas (Turgut et al., 2009; Altunkaynak et al., 2011b).

Thus, point counting test grid was used for the estimation of sectioned area in the pancreas. The point density of the point counting grid was designed to obtain an appropriate coefficient of error (CE) for interesting area in images of the serial sections (Altunkaynak and Altunkaynak, 2007; Turgut et al., 2009). CE and coefficient of variation (CV) were estimated according to Gundersen and Jensen' formula (Gundersen, 1986; Altunkaynak et al., 2011a). The test grid with sys- tematic array of points was randomly placed on the screen of PC. The volume of each interesting area (all pancreas section) in pancreas sections was estimated with following formula:

\section{Volume $=\mathbf{t} \times \mathbf{a} / \mathbf{p} \times \mathbf{\Sigma} \mathbf{P}$}

("t", section thickness; "a/p", representing area of each point on the point counting grid; " $\Sigma \mathrm{P}$ ", total number of the points hitting the interesting area)

Then, total volume of selected sections from each pancreas was multiplied with five (the fraction ratio) to estimate pancreas volume (pancreas volume $=$ total volume of selected sections $\mathrm{x}$ 5).

\section{Numerical density of islet cell nuclei and mean nuclear height of islet cell:}

The selection of the physical disector pairs was done as described by Sterio (1984). Based on the findings obtained from a pilot study, pairs from every fifth section were chosen randomly, and in this way approximately $15-20$ section pairs were obtained and evaluated. This number is in an acceptable range for stereological analysis (Unal et al., 2004; Sarsilmaz et al., 2007). Disector pairs were taken from the tissue at a known interval, until the tissue sample was exhausted. Two consecutive sections were mounted on each slide. Photographs of adjacent sections were taken with a digital camera at a magnification of $x 400$. Nuclei of islet cell seen in the reference section but not in the look-up section were counted (Aslan et al, 2006b). To increase the countable particle (islet cell nucleus) number, we exchanged the role of sections in the second step (Aslan, 2006a, Kiki et al., 2007). An unbiased counting frame (Altunkaynak et al., 2011a) was placed on the reference and the look-up sections on the screen of the PC to perform the counting according to the disector counting method. The bottom and the left hand edges of the counting frame are considered to be the forbidden (exclusion) lines together with the extension lines.

Other boundaries of the frame and the top-right corner were considered to be inclusion points and any particle that hit these lines or was located inside the frame was counted as a disector particle (Altunkaynak et al., 2012).

It was adjusted the appropriate size of unbiased counting frame to count approximately 600 islet cells from each sample. The dimension of counting frame at PC screen, used in this study was $100 \mathrm{~mm} \times 100 \mathrm{~mm}$ and the real dimension of this counting frame $\left(6.250 \times 10-2 \mathrm{~mm}^{2}\right)$ was estimated by the following formula:

Real dimension=Screen Size of Frame $/$ Total Magnification of Microscope

The mean numerical density of islet cells [Nv(islet cell)] in per $\mathrm{mm}^{3}$ was estimated using the following formula (Sterio, 1984 ; Unal et al., 2004).

\section{$\mathrm{Nv}($ islet cell $)=\Sigma Q-($ islet cell $) / t \cdot A$}

Where $\Sigma$ Q-islet cell is the total number of nuclei counted in the reference section; $t$ is the mean section thickness ( 5 $\mu \mathrm{m})$, and $\mathrm{A}$ is the area of the unbiased counting frame.

The mean nuclear height (H(nucleus)), which is a measure of the size of nucleus that depends on the section plane, was estimated by the following equation (Aslan et al., 2006a, 
Kiki et al., 2007).

$\mathrm{H}($ nucleus $)=[\Sigma \mathrm{Q}$ (nucleus) $/ \Sigma \mathrm{Q}-($ nucleus $)] \mathrm{x} \mathrm{t}$

Where $\Sigma \mathrm{Q}$ (nucleus) is the total number of nuclei counted in the reference section, $\Sigma$ Q-(nucleus) is the total number of disector nuclei counted in the reference section, and $t$ is the mean section thickness $(1 \mu \mathrm{m})$.

The total number of islet cell (TN (islet cell)) in the rat pancreas was estimated by the following equation:

$\mathrm{TN}($ islet cell $)=\mathrm{Nv}($ islet cell $) \times \mathrm{PV}$

Where $\mathrm{Nv}$ (islet cell) is the numerical density of pancreatic islet cell nuclei ( $\mathrm{NV}$ (islet cell)) in $\mathrm{mm}^{3}$; PV, pancreas volume $\left(\mathrm{mm}^{3}\right)$ estimated by using Cavalieri principle.

\section{Correction for tissue shrinkage}

Shrinkage will affect all stereological size estimators including volume (Christensen et al., 2007; Kannekens et al., 2006).

Measurements were made to quantify shrinkage caused by fixation and histological procedures. For this purpose, the volume of removed fresh pancreas was calculated by water immersion method. The volume of each pancreas after processing, cutting and dying was estimated with the Cavalieri method (Gundersen and Jensen, 1987).

The volume shrinkage was then calculated as:

\section{volume shrinkage $=1$ - $($ volume after $/$ volume before $)$}

\section{Statistical analyses:}

Microsoft ${ }^{\circledR}$ SPSS Version 13.0 for Windows was used for statistical analyses. Mann Whitney-U test was applied to compare volume of pancreas, and also mean numerical density, total number and mean nuclear height of islet cells in different age groups each other. All statistical values under 0.05 were considered as statistically significant.

\section{Results}

\section{Stereological results}

All stereological results were summarized in Table 1.

\section{Mean numerical density of Islet cell nuclei ( $\mathrm{Nv}(\mathrm{ic}))$}

The mean numerical density of islet cells of 20-days-old fetuses and newborn rats were shown in Table 1 . There were a significant difference among this groups in terms of the numerical density of islet cells $(\mathrm{p}<0.05)$.

\section{Table 1. Stereological estimations}

\begin{tabular}{lcc} 
Estimation & $\begin{array}{c}\text { 20-days-old } \\
\text { fetuses }\end{array}$ & Newborns \\
\hline Mean numerical density of Islet cell & 6733 & 11281 \\
Nuclei $\left(\right.$ cell $\left./ \mathrm{mm}^{3}\right)$ & & \\
Mean nuclear height $(\mu \mathrm{m})$ & 6.4 & 5.7 \\
Total number of Islet cell Nuclei & 67200 & 133689 \\
Pancreas volume $\left(\mathrm{mm}^{3}\right)$ & 9.98 & 11.85 \\
\hline
\end{tabular}

\section{Mean nuclear height (NH(ic))}

Mean nuclear height of islet cells of newborn rats and 20 -days-old rat fetuses were shown in Table 1. There were a significant difference among this groups in terms of the mean nuclear height of islet cells $(p<0.05)$ in favor of the fetuses.

Total number of Islet cell Nuclei (TN (icn))

The total number of islet cell's of 20-days-old rat fetuses and newborns were shown in Table 1 . There were a significant difference among this groups in terms of the total number of islet cells $(\mathrm{p}<0.05)$. They was more in newborns than that of the fetuses.

\section{Pancreas volume estimation}

Pancreas volume of newborns and 20 days rat fetuses were shown in Table 1. There were a significant difference among this groups in terms of the pancreas volume $(\mathrm{P}<0.05)$. They was more in newborns than that of the fetuses.

All volumetric values of pancreas were estimated by Cavalieri principle on the series of toluidine blue stained sections.

\section{Histological results \\ Light microscopical results}

Pancreas samples of 20-days rat fetuses were surrounded with a thin of connective tissue capsule. Acini were very few and they were not luminalized. Epithelium of acini appeared as stratified and consisted of euchromatic nucleated cells. Moreover, mitotic figures were seen between these cells. Histologic views of the secretory ducts were not distinguished from acini (Fig. 1a,c).

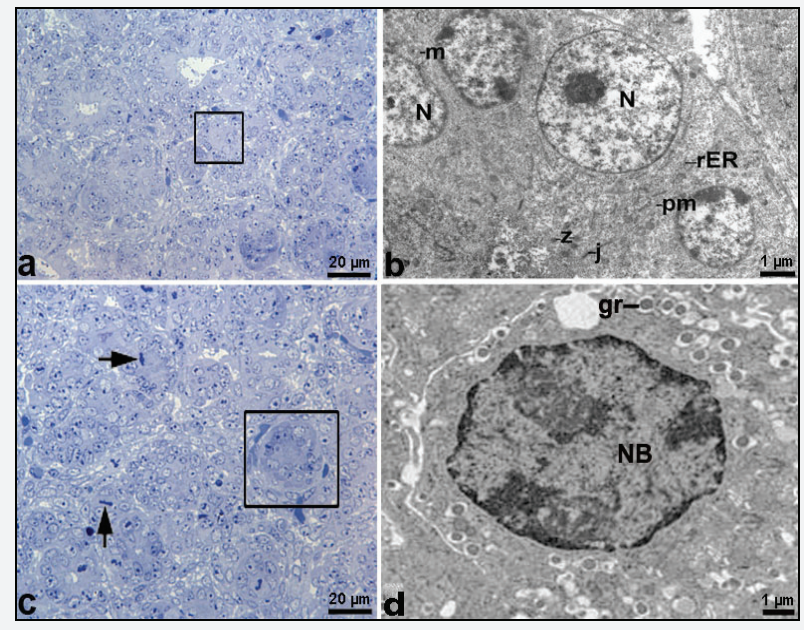

Fig. 1. Light (a, c) and electron microghraps (b, d) which were obtained from 20 days old rat fetuses. Black-framed areas show Langerhans islet (c) and serous acinus (a). Arrows, mitotic figure; rER, rough surfaced endoplasmic reticulum; , pm, plasma membrane; Z, Zymogen granule; $\mathrm{m}$, mitochondrion; $\mathrm{j}$, junction between cells, $\mathrm{N}$; nucleus of the acinar cell, NB, nucleus of the Beta Cell; gr, insulin granules.

Zymogen granules were observed in serous acini cells of newborn rats. Duct cells consisted by dense cytoplasma and secretory vesicle. Langerhans islets were more mature than those of 20 days old fetuses and endocrine cells were distinguished easily (Fig. 2a,c).

\section{Electron microscopical results}

In electron microscopical examinations about 20 days old fetuses, cells of acini and ducts were connected tightly to each other also they were seen near the lumen. Acinar cells include a few and small zymogen granules. But they have mitochondria and abundant microtubules. Islet cells did not differ from 
each other in terms of the content (Fig.1b). Also endocrine cells of the islets contained large beta cells which have peripherally localized insulin granules (Fig. 1d).

In serous acini belongs to newborn group, zymogen granules were more and larger than those of the 20 days old fetuses (Fig. 2d). Islets were highly mature according to those of the 20 days old fetuses and the beta cells were distinguished from other islet cells in terms of small granules in these samples (Fig. 2b).

\section{Discussion}

The embryonic pancreas has, during recent years, proven to be an excellent system for the study of development and differentiation (Avrahami and Kaestner, 2012; Serup, 2012). In these studies generally laboratory animals were used to aid in the extrapolation to human assessment. Because, in small laboratory animals; such morphological changes happen faster than humans (Hew and Keller 2003; Polla et al., 2004).

Stereology is a set of the some simple and efficient methods for quantification of two-dimensional microscopic sections which is specifically tuned to provide reliable data about ones. So the methods allow to understand real three dimensional characteristics of these structures (Aslan et al., 2006a, Kiki et al., 2007).

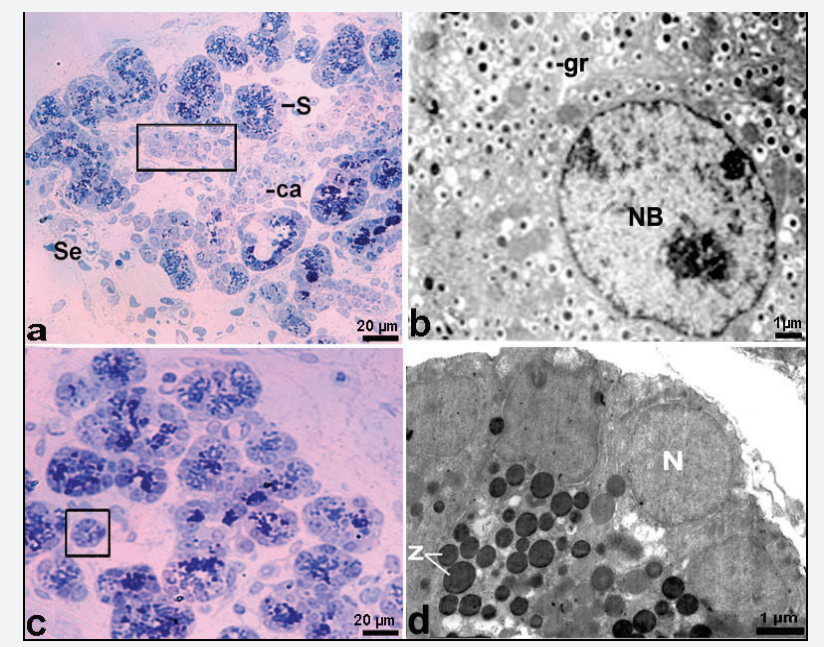

Fig. 2. Light (a, c) and electron micrographs (b, d) which were obtained from newborn rat bubs. Black- framed areas show Langerhans's islet in a and serous acinus in C. $\mathrm{NB}$, nucleus of the Beta Cell; gr, insulin granule; Z, Zymogen granule; $\mathrm{N}$; nucleus of the acinar cell.

In the fetal and neonatal pancreas, there are variable, but higher proportion non-islet endocrine cells than in the adult, and the percentage of pancreas occupied by endocrine tissue in the neonate is much higher than in the adults. This diffuse involvement might suggest a pathological excess of endocrine tissue (Keeling and Khong, 2007). In such a case, it is essential to clearly understand, and eventually control pancreatic cell process for learning developmental process and also preventing many pancreas pathologies such as hypoglycemia.

In the literature there are many studies about pancreas structure. Some of these are performed with clinical, histopathological or biochemical methods. However, number of quantitative and/or embryological studies which were made with unbiased stereological methods is a few. Further; none of the stereological and/or embryological studies evaluated histological structure of pancreas at electron microscopical level. So, in the current study, we aimed to determine fetal and neonatal structure of rat pancreas with stereological and histological approaches. Developmental stage was considered in fetal stage (20th days) and newborns (in the postnatal first week). For this aim, we estimated total pancreas volume, mean numerical density, mean nuclear height and also total number of cell number. Also, our histological evaluations were made at light and electron microscopical levels.

According to our results, a significant difference was found in terms of mean numerical density of islet cells between 20 days fetuses and newborns (in post natal third day; $\mathrm{n}=10$ ) and volumetric results showed that it were important differences in total pancreas volume and volume of islets of 20 days fetus and newborns.

When pancreas samples histologically evaluating under light microscopy, pancreas samples of 20-days rat fetuses were surrounded with a thin of connective tissue capsule. Acini were very few and they were not luminalized. Epithelium of acini appeared as stratified and consisted of euchromatic nucleated cells. Moreover, mitotic figures were seen between these cells. Histologic views of the secretory ducts were not distinguished from acini.

Besides, in electron microscobical examinations of 20 days old fetuses, acini and duct cells are connected tightly to each other. Acinar cells included a small number of zymogen granules, mitochondria and abundant microtubules. Islet cells did not differ from each other in terms of the content.

In serous acini of newborn group, zymogen granules and other secretory granules were greater. Channel cells which contain denser cytoplasm and abundant mitochondria were seen. Islets of Langerhans were a more mature view and the beta cells were distinguished. As a result, our study presented more detailed knowledge than previous studies about histological and morphometric structure of developing pancreas. The findings suggest that differences in the pancreas structure between 20 days fetuses and newborns may be related to nutrition. So, food perhaps the mother's milk plays a role as triggering agent for pancreas development.

\section{REFERENCES}

Altunkaynak, B.Z., Altunkaynak, M.E., 2007. Relationship of body weight and volume of liver: A morphometrical and stereological study. Saudi Med. J. 28, 478-481.

Altunkaynak, B.Z., Ozbek, E., Aydin, N., Aydin, M.D., Altunkaynak, M.E., Vuraler, O., Unal, B., 2011a. Effects of haloperidol on striatal neurons: Relation to neuronal loss (a stereological study). Folia Neuropathol. 49, 21-27.

Altunkaynak, B.Z., Unal, D., Altunkaynak, M.E., Halici, Z., Kalkan, Y., Keles, O.N., Aksak, S., Selli, J., Unal, B., 2012. Effects of diabetes and ovariectomy on rat hippocampus (a biochemical and stereological study). Gynecol. Endocrinol. 28, 228-233. 
Altunkaynak, M.E., Altunkaynak, B.Z., Unal, D., Yildirim, S., Can, I., Unal, B., 2011b. Stereological and histological analysis of the developing rat heart. Anat. Histol. Embryol. 40, 402-410.

Aslan, H., Altunkaynak, B.Z., Altunkaynak, M.E., Vuraler, O., Kaplan, S., Unal, B., 2006a. Effect of a high fat diet on quantitative features of adipocytes in the omentum: An experimental, stereological and ultrastructural study. Obes. Surg. 16, 1526-1534.

Aslan, H., Songur, A., Tunc, A.T., Ozen, O.A., Bas, O., Yagmurca, M., Turgut, M., Sarsilmaz, M., Kaplan, S., 2006b. Effects of formaldehyde exposure on granule cell number and volume of dentate gyrus: a histopathological and stereological study. Brain Res. 1122, $191-200$.

Avrahami, D., Kaestner, K.H., 2012. Epigenetic regulation of pancreas development and function. Semin. Cell Dev. Biol. 23, 693-700.

Christensen, J.R., Larsen, K.B., Lisanby, S.H., Scalia, J., Arango, V., Dwork, A.J., Pakkenberg, B., 2007. Neocortical and hippocampal neuron and glial cell numbers in the rhesus monkey. Anat. Rec. (Hoboken). 290, 330-340.

Chung, J.H., Lim, G.Y., Song, Y.T., 2007. Congenital true pancreatic cyst detected prenatally in neonate: A case report. J. Pediatr. Surg. 42, 27-29.

Dixon, M., Crawford, D., Teasdale, D., Murphy, J., 2009. Nursing the Highly Dependent Child or Infant: A Manual of Care. Blackwell Publishing Ltd, United Kingdom, Oxford.

Gundersen, H.J., 1986. Stereology of arbitrary particles. A review of unbiased number and size estimators and the presentation of some new ones, in memory of William R. Thompson. J. Microsc. 143, 3-45.

Gundersen, H.J., Jensen, E.B., Kiêu, K., Nielsen, J., 1999. The efficiency of systematic sampling in stereology-re considered. J. Microsc. 193, 199-211.

Gundersen, H.J.G., Jensen, E.B., 1987. The efficacy of systematic sampling in stereology and its prediction. J. Microsc. 147, $229-263$.

Hew, K.W., Keller, K.A., 2003. Postnatal anatomical and functional development of the heart: A species comparison. Birth. Defects. Res. B. Dev. Reprod. Toxicol. 68, 309-320.

Hill, Dr. M., 2007. UNSW Embryology Endocrine Development, the university of New South Wales, Sydney. http://php.med.unsw.edu.au/embryology/index.php?title=Main_Page. Accepted: 23.02.2012

Kannekens, E.M., Murray, R.D., Howard, C.V., Currie, J., 2006. A stereological method for estimating the feto-maternal exchange surface area in the bovine placentome at 135 days gestation. Res. Vet. Sci. 81, 127-133.

Keeling, J.W., Khong, T.Y., 2007. Fetal and neonatal pathology. 4th edition. Springer-Verlag London Limited. pp: 687-688.

Kiki, I., Altunkaynak, B.Z., Altunkaynak, M.E., Vuraler, O., Unal, B., Kaplan, S., 2007. Effect of high fat diet on the volume of liver and quantitative feature of Kupffer cells in the female rat: A stereological and ultrastructural study. Obes. Surg. 17, 1381-1388.

Marchetti, P., Bugliani, M., Lupi, R., Marselli, L., Masini, M., Boggi, U., Filipponi, F., Weir, G.C., Eizirik, D.L., Cnop, M., 2007. The endoplasmic reticulum in pancreatic beta cells of type 2 diabetes patients. Diabetologia. 50, 2486-2494.

Polla, B., D’Antona, G., Bottinelli, R., Reggiani, C., 2004. Respiratory muscle fibres: Specialisation and plasticity. Thorax. 59, 808-817.

Sarsilmaz, M., Kaplan, S., Songur, A., Colakoglu, S., Aslan, H., Tunc, A.T., Ozen, O.A., Turgut, M., Baş, O., 2007. Effects of postnatal formaldehyde exposure on pyramidal cell number, volume of cell layer in hippocampus and hemisphere in the rat: A stereological study. Brain Res. 1145, 157-167.

Serup, P., 2012. Signaling Pathways Regulating Murine Pancreatic Development. Semin Cell Dev Biol. 23, 663-672.

Sterio, D.C., 1984. The unbiased estimation of number and sizes of arbitrary particles using the disector. J. Microsc. 134, $127-136$.

Turgut, M., Kaplan, S., Ünal, Z.B., Altunkaynak, B.Z., Ünal, D., Şahin, B., Bozkurt, M., Yurtseven, M.E., 2009. Effects of pinealectomy on morphological features of blood vessel in chicken: An electron microscopic and stereological study. J. Exp. Clin. Med. 26, 112-118.

Unal, B., Özbek, M.E., Aydın, M.D., Aydın, N., Bulucu, Z., Vuraler, O., Odaci, E., Sahin, B., Kaplan, S., 2004. Effect of haloperidol on the numerical density of neurons and nuclear height in the rat hippocampus: A stereological and histopathological study. Neurosci. Res. Commun. 34, 1-9. 